Article

\title{
Social Networks as a Coping Strategy for Food Insecurity and Hunger for Young Aboriginal and Canadian Children
}

\section{Benita Y. Tam *, Leanne Findlay * and Dafna Kohen}

Health Analysis Division, Statistics Canada/150 Tunney’s Pasture Driveway, Ottawa, ON K1A 0T6, Canada; E-Mail: benita.tam@statcan.gc.ca

* Authors to whom correspondence should be addressed; E-Mails: benita.tam@gmail.com (B.Y.T.); leanne.findlay@statcan.gc.ca (L.F.); Tel.: +1-613-790-6376 (B.Y.T.); Tel.: +1-613-951-4648 (L.F.); Fax: +1-613-951-3959 (B.Y.T. \& L.F.).

Received: 3 June 2014; in revised form: 23 July 2014 / Accepted: 20 August 2014 /

Published: 11 September 2014

\begin{abstract}
Traditional foods and food sharing are important components of Aboriginal culture, helping to create, maintain, and reinforce social bonds. However, limitations in food access and availability may have contributed to food insecurity among Aboriginal people. The present article takes a closer examination of coping strategies among food insecure households in urban and rural settings in Canada. This includes a comparative analysis of the role of social networks, institutional resources, and diet modifications as strategies to compensate for parent-reported child hunger using national sources of data including the Aboriginal Children's Survey and the National Longitudinal Survey of Children and Youth. Descriptive statistical analyses revealed that a majority of food insecure urban and rural Inuit, Métis, and off-reserve First Nations children and rural Canadian children coped with hunger through social support, while a majority of urban food insecure Canadian children coped with hunger through a reduction in food consumption. Seeking institutional assistance was not a common means of dealing with child hunger, though there were significant urban-rural differences. Food sharing practices, in particular, may be a sustainable reported mechanism for coping with hunger as such practices tend to be rooted in cultural and social customs among Aboriginal and rural populations.
\end{abstract}

Keywords: Aboriginal Children’s Survey; Canada; food insecurity; hunger; Inuit health; National Longitudinal Survey of Children and Youth 


\section{Introduction}

Food security, as defined by The World Food Summit in 1996, "exists when all people, at all times, have physical and economic access to sufficient, safe, and nutritious foods to meet their dietary needs and food preferences for an active and healthy life” [1]. Thus, to be food insecure is to have limited access and availability of nutritious and preferred foods. The degree of food insecurity may range in severity. For example, a lesser degree of food insecurity may be the uncertainty of being able to access food in a "socially acceptable way" (e.g., purchasing groceries versus stealing food) [2]. Moderate food insecurity can be described by the consumption of lower quality foods, and severe food insecurity may include irregular eating patterns and limited food consumption, such as skipping meals [3]. Reported hunger is an extreme form of food insecurity [4,5], which may also be referred to as "very low food security" [6]. Severely food insecure households are more likely to use coping strategies that reduce food intake [7,8] and consequences often include physical and psychological health effects [9].

Food insecurity is a pressing issue affecting the health and well-being of many individuals worldwide. In Canada, Aboriginal people are generally at greater risk of food insecurity than are non-Aboriginal people [3]. In 2004, the odds of food insecurity among Aboriginal households were approximately 5 times that of non-Aboriginal households [3]. Rates of moderate and severe food insecurity among Aboriginal households were $19 \%$ and $14 \%$, respectively, compared to $6 \%$ and $3 \%$ among non-Aboriginal households [3].

Food insecurity and hunger also have an impact on child health and well-being. Food insecure children are at greater risk of hospitalization and poorer general health, physical health (e.g., higher $\mathrm{BMI}$ ), and health-related quality of life [10-12]. Food insecurity among children may also decrease social skills, academic performance, and psychosocial functioning [11-13]. As food insecurity and hunger affect the overall health of children, it is important to understand available and relevant coping behaviors for food insecurity.

\subsection{A Conceptual Model of Food Security for Aboriginal People}

The conceptual model of food security presented in this review is based on a model described in Ford [14]; an adapted version of the model is presented in Figure 1. As shown in Figure 1, food security is based on three components: food access, food availability, and food quality [14]. Food access refers to the affordability, allocation, and preference of food [14], which includes sufficient traditional and/or store bought food of preference and of nutritional value [15]. Factors influencing food access for Aboriginal people include traditional skills, legislation, cost, income, market access, and community support $[14,16]$. Food availability refers to the production, distribution and exchange of food, which includes available and sufficient food to meet the intake and nutritional needs of individuals and households [17]. Factors affecting food availability include migration patterns of animals, legislation, and environmental stability [14]. Food quality refers to the nutritional value, social value, and safety of food, also including the ability to secure safe foods with high nutritional, social, and cultural value [15]. Factors affecting food quality include the health of game animals and environmental contamination [14]. The present report considers cultural aspects which may relate to 
food access, availability and quality as they pertain to coping mechanisms employed to deal with hunger between urban and rural Aboriginal and Canadian children.

Figure 1. Conceptual model of food security [14].

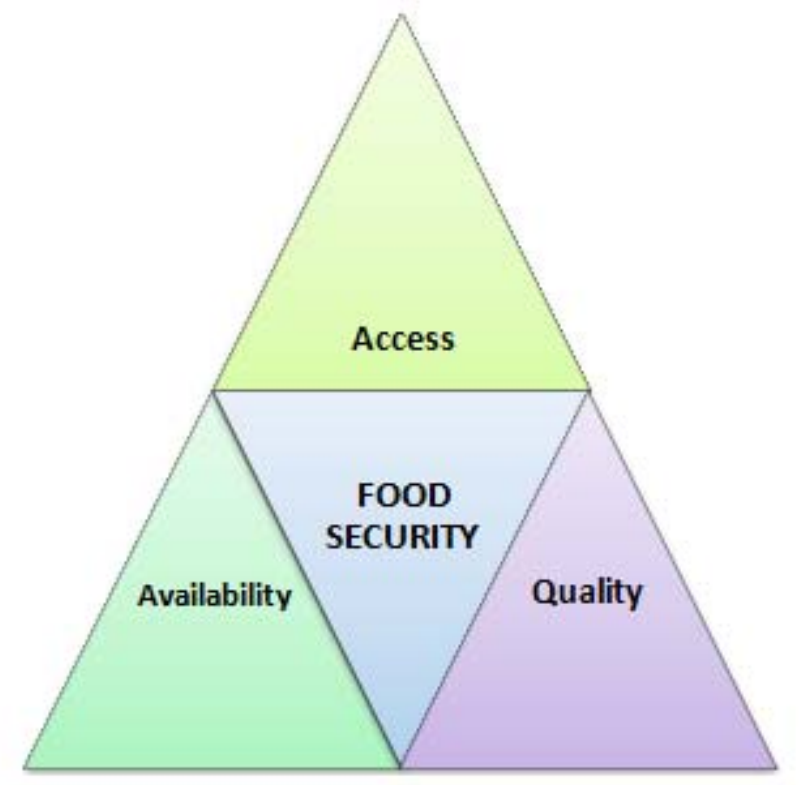

\subsection{Urban-Rural Differences in Food Insecurity}

Geographical differences in the prevalence of food insecurity as well as in adaptation strategies to cope with food insecurity may exist. For example, urban households may be more likely to experience food insecurity and hunger than rural households [18]. The prevalence of food insecurity may also differ by the level of metropolitan influence, that is, proximity to an urban center. Nord and colleagues [19] found that the prevalence of food insecurity was greater in metropolitan centers than regions outside of metropolitan zones. Such differences in the prevalence of food insecurity may be influenced by the availability of resources. For example, people living in rural areas may be more likely to plant their own garden than those living in urban areas [20]. This type of resource may increase access and availability of nutritious foods. Conversely, people living in urban areas may have greater access to affordable transportation to local food outlets than those in rural areas [20], which may increase affordability of food. Thus, although food insecurity may differ between urban and rural areas, available resources within these geographical regions may also influence differences in adaptation strategies.

On the other hand, determinants of food insecurity may be similar between urban and rural populations [21,22]. These factors include socio-economic status, food costs and affordability, food availability and access, environmental change, and family size [23-25]. As studies have found, food insecurity may be driven by underlying disparities involving income inequality, residential context, and available social assistance policies [4,26]. It is rather the contextual factors of an individual, such as income, that influence accessibility, availability, affordability, and quality of food [22].

The next section of this review incorporates parent-reported data from the Aboriginal Children's Survey (ACS) (2006) and the National Longitudinal Survey of Children and Youth (NLSCY) (combined cycles 5,6,7 and 8) (2002-2009) to identify parent/guardian reported hunger and coping 
strategies for hunger. In both surveys, hunger was measured using a single-item hunger indicator: "Has this child ever experienced being hungry because the family has run out of food or money to buy food?" Those who reported "yes" were then asked how often (the child experienced hunger) (“occasionally, not a regular occurrence”, "every few months”, "more often than end of each month”, and "regularly, end of the month") and about the coping strategies employed to deal with hunger. The ACS, developed by Statistics Canada and Aboriginal advisors from across Canada, was designed to provide data on early development and the social and living conditions of Inuit, Métis, and off-reserve First Nations children aged $0-5$ years old. The NLSCY, conducted by Statistics Canada and Employment and Social Development Canada (formerly Human Resources and Skills Development Canada), was designed to collect data on factors affecting a child's social, emotional, and behavioral development. Age range was restricted to $0-5$ years old using NLSCY data to coincide with the age range available from the ACS.

Using these two data sources, we compared hunger and coping strategies for Métis and off-reserve First Nation children aged $0-5$ years old $(n=8724)$, Inuit children aged $0-5$ years old $(n=1691)$, and Canadian children aged $0-5$ years old $(n=47,967)$. Métis and off-reserve First Nation children were grouped together as patterns for the two groups were found to be similar (results available from the authors upon request) and due to small sample sizes of child hunger among Métis and off-reserve First Nation children. We also compared rates of parent-reported hunger and coping strategies between urban and rural areas: urban $(n=6632)$ and rural $(n=2092)$ Métis and off-reserve First Nation children, urban $(n=1097)$ and rural $(n=594)$ Inuit children, and urban $(n=41,246)$ and rural $(n=6721)$ Canadian children.

Geographical region (urban vs. rural) was based on the metropolitan influence zone. The metropolitan influence zone conceptualizes areas (i.e., census subdivisions) outside of census metropolitan areas and census agglomerations. Census subdivisions are assigned a level of metropolitan influence (strong, moderate, weak, or no influence) based on the proportion of the employed labor force that commute to work in a census metropolitan area or census agglomeration [27]. In the present report, urban refers to a census metropolitan area, census agglomeration, and a strong or moderate metropolitan influence zone. Rural refers to a weak to no metropolitan influence zone. Due to small sample sizes, urban Inuit children also included those residing in a weak metropolitan influence zone; rural Inuit children only included those residing in a zone with no metropolitan influence.

\subsection{Prevalence of Hunger among Inuit, Métis, off-Reserve First Nation and Canadian Children in Urban and Rural Areas in Canada}

Previous reports based on ACS data have revealed that the rate of reported hunger is $23 \%$ among Inuit children, 3\% among Métis children, and 5\% among off-reserve First Nation children younger than 6 years old $[28,29]$. This compares to $1 \%$ of all children from the NLSCY sample, suggesting that reported hunger is higher among Aboriginal children than Canadian children in general.

Geographical differences in the prevalence of reported hunger for Inuit and Canadian children living in urban versus rural areas also exist. The rate of hunger was reported as being higher for rural Canadian children compared to urban and higher for Inuit children in rural areas compared to Inuit children in urban areas. For Canadian children, $0.6 \%$ in urban areas reported experiencing hunger 
compared to $1 \%$ in rural areas $(p<0.001)$. For Inuit children, $19 \%$ in urban areas had experienced hunger compared to 33\% of Inuit children in rural areas $(p<0.001)$. In contrast, the rate of hunger was similar between urban Métis and off-reserve First Nation children and their rural counterparts. In urban areas, 4\% of Métis and off-reserve First Nation children were reported as experiencing hunger compared to $3 \%$ in rural areas $(p>0.05)$.

\section{Coping Mechanisms to Deal with Hunger}

Various coping mechanisms, actions, or strategies can be used to manage food insecurity and hunger. Coping mechanisms often include "formal” or "informal” approaches. An example of a formal approach is the use of institutional food resources, such as food banks and soup kitchens, and examples of an informal approach include food sharing and reduced food consumption. We examined the reported use of these three coping mechanisms for hunger among parents of Aboriginal and Canadian children in general: seeking help from institutions, seeking assistance from relatives and/or friends, and skipping meals and/or cutting back on food consumption. The next section describes our findings based on the ACS for Métis, off-reserve First Nations, and Inuit children and the NLSCY for Canadian children in terms of formal and informal coping mechanisms, taking into consideration differences in geography.

\subsection{Formal Approach: Institutional Food Resources}

Institutional food resources are classified as a formal redistribution of food installed by governments to reduce the rate of food insecurity [20]. Examples include food banks, food stamp programs, meal programs, and community gardens [20]. In the USA, for example, low-income areas in particular have a greater reliance on food stamp programs than high income areas [26]. The effectiveness of institutional food assistance programs, however, has been questioned, as not all households in need are able to access such resources, and individuals participating in such programs are not always able to obtain nutritious foods such as fruits and vegetables [30].

Seeking help from institutions (e.g., food stamps, food banks) is a formal redistribution of food resources, which may be a coping option more frequently used by urban food insecure households. However, this was not a prominent coping strategy reported by parents as per our descriptive analyses. Most parents (Aboriginal and Canadian children in general) did not report seeking help from institutions to cope with hunger, although significant differences were found between urban and rural populations. For all three Aboriginal groups and Canadian children in general, the rate of institutional assistance was higher in urban areas. Households of urban food insecure Métis and off-reserve First Nation children (44\%), Inuit children (18\%), and Canadian children (34\%) had higher rates of seeking institutional assistance than their rural counterparts (Métis and off-reserve First Nation children $=15 \%(p<0.001)$, Inuit children $=4 \%(p<0.001)$, Canadian children $=26 \%$. (Due to a small sample size, this result for Canadian children should be interpreted with caution, $p>0.05$ ).

These findings coincide with past research which has found that a majority of food insecure households do not access institutional food resources, such as food banks, despite food availability [30,31]. Loopstra and Tarasuk [30] found that among an urban low-income group in Toronto, Canada (75\% of which were food insecure), a small percentage (23\%) accessed food banks. 
Food insecure households may not access food banks due to unsuitable food options, social stigma, perceived unnecessary need, limited information, limited access due to transportation issues, and difficulty in obtaining approval for food bank access [30]. Kirkpatrick and Tarasuk [32] also suggested that the prevalence of food insecurity of a region may not change despite an increase in food assistance programs. Contextual factors of a household/community, such as access to resources and transportation, need to be taken into consideration when examining food insecurity, as a greater number of food resources does not necessarily equate to higher food security. Thus, urban-rural differences may not be the only contributing factors to usage of institutional food assistance programs [33].

The present study showed that seeking institutional assistance was not a commonly reported means of dealing with child hunger among rural Aboriginal or Canadian groups. This may be because institutional food resources may only be available in some of the larger rural Aboriginal communities in Canada [34]. Only in recent years have studies documented the use of food programs in rural Aboriginal communities. For example, in Inuvik, Northwest Territories, Canada, community food programs including a food bank, a shelter, and a soup kitchen (called Soup and Bannock), are available to local Inuit community members [35]. In Fort Albany, Ontario, Canada, a community greenhouse and school snack programs were recently implemented to supplement the diet of First Nation community members and children [36]. However, the use of formal coping strategies to deal with hunger may be a less common option for smaller rural Aboriginal communities due to the unavailability of such resources; informal strategies may be more common.

\subsection{Informal Approach: Food Sharing}

Food sharing, perhaps with family and friends, is an example of an informal coping strategy which may be employed to deal with food insecurity and hunger. Informal coping mechanisms may include a redistribution of food, where individuals participate in a reciprocal exchange of resources [20]. Reciprocal exchanges of resources include exchanging food for domestic help (e.g., gardening), sharing food, and lending money to purchase food. Such reciprocal practices stem from social responsibility, which tend to be more prominent among kin groups and rural communities [37,38].

Seeking assistance from relatives and/or friends is an informal reciprocal exchange of food resources that may increase food intake. This particular coping mechanism is prominent among food insecure Aboriginal and rural Canadian children. Among food insecure Métis and off-reserve First Nations children, 54\% from urban and 68\% from rural areas sought help from relatives and friends ( $p>0.05)$. Similarly, although a majority of urban (75\%) and rural (89\%) food insecure Inuit children sought assistance from relatives and friends, rural Inuit children were significantly more likely to be reported to use this strategy ( $p<0.001$ ). This may be attributed to greater availability of other coping options in urban versus rural areas, such as the formal mechanisms described earlier [39]. For Canadian children, the pattern was similar, with a majority of those identified as food insecure in rural areas (83\%) seeking assistance from relatives and friends compared to $41 \%$ in urban areas who coped in this way $(p<0.01)$.

Food sharing is a common cultural practice among Aboriginal people in Canada and Native American people in USA [36,40-42]. In particular, sharing food may be a coping mechanism to increase food access to traditional foods among Aboriginal people. Sharing food connects the 
community and builds kinship ties and partnerships [43]. Among Inuit communities, redistribution of traditional foods reflects acts of affection with family and community members and acts of respect with extended family members [44]. In other communities, the act of sharing reflects a culture of egalitarianism, strengthening the community, and preventing societal division [43].

Similar forms of informal assistance include communal meals and friends/relatives purchasing food for an individual, consuming a meal with an individual, and cooking for an individual $[41,45,46]$. As an illustration, in an Inuit community in Nunavut, Canada, families congregated at one place for communal gatherings, which included participating in traditional activities, socializing, and preparing food [46]. An increase in family support may also increase healthier dietary habits for individuals [45,47]. Epple and colleagues [45] found that Native Americans with family support were more likely to have health benefits associated with healthy dietary habits (lower levels of triglyceride and cholesterol). The combined effort in obtaining and preparing food communally represents a reciprocal exchange of resources that increases food availability for those with limited access to cultural and healthy foods.

Specifically regarding geographical differences, others have also suggested that individuals living in rural communities are more likely to share food with family and friends than those living in urban communities [20]. For example, rural food insecure residents in Iowa, USA sought informal social support (e.g., call someone for help; seek assistance from friends/family for grocery shopping or cooking) and participated in the mutual exchange of food [48]. Compared to urban households, there may be a greater dependence on food sharing practices among low-income rural households due to limited resources and options [49,50]. Garasky and colleagues [48] identified high food prices, limited grocery outlets, and transportation restrictions as barriers to food access among rural food insecure residents.

Alternatively, barriers to food access and availability (e.g., low income) may not be the only factors influencing greater food sharing practices among rural areas. Even when controlling for income, food sharing practices among rural groups remained higher than for urban groups [20]. Rural households may participate in food sharing due to a greater sense of social responsibility [51]. Quandt and colleagues [37] found that rural community members shared food with others to maintain social relationships and a sense of community. Similarly, rural residents were two times more likely to support others in the community, particularly kin members, than their urban counterparts [50]. Sharing food among rural elders may also be a source of social activity and human contact [37]; such reciprocity practices are not solely conducted for the purpose of coping with food access issues. Thus, the mutual exchange of resources may increase the sense of community and collectiveness in rural communities.

\subsection{Informal Approach: Reduced Food Intake}

Informal coping mechanisms may also include a decrease in food intake, including the modification of eating patterns and a reduction in food consumption, restricted food sharing practices to conserve resources, and food replacement. For example, in Canada, primary caregivers of food insecure households often skipped meals so that their child could eat [52,53]. Inuit women in Nunavut, Canada would alter eating practices due to socioeconomic stress and limited resources [24]. Other households 
may refrain from hosting a dinner to reduce food expenditure [9] or make unhealthy food decisions when faced with limited resources [54].

Skipping meals and/or cutting back are coping mechanisms that reduce food intake, which were found to be more prominent among urban food insecure Canadian children and less common among Aboriginal and rural Canadian children. NLSCY/ACS data suggests that parents of urban Canadian children were more likely to report coping with hunger by skipping meals and/or cutting back (59\%) than rural Canadian children (9\%) $(p<0.001)$. In comparison, fewer food insecure Métis and off-reserve First Nation (urban $=27 \%$, rural $=33 \% ; p>0.05$ ) and Inuit (urban $=27 \%$, rural $=19 \%$; $p<0.05$ ) parents/children reduced food intake to cope with hunger.

Even with possibly higher availability of food resources due to formal coping approaches in urban centers [30,31], parents of urban food insecure Canadian children reported that they coped with hunger through changes in food consumption patterns more frequently than rural food insecure Canadian children. Other research has also found that people living in urban and suburban areas may be more likely to reduce food intake, e.g., skipping meals [7], to cope with food insecurity than people living in rural areas [18]. In the USA, food insecure families reported a preference for reducing food consumption over institutional assistance, although assistance from social support networks preceded preferences for dietary changes [55].

Possible explanations for the use of food reduction strategies to cope with food insecurity and hunger among those living in urban areas may be due to differences in social resources and supports or barriers that limit the access to food resources. First, a movement towards individualism and a lack of collectiveness in urban areas [56,57] may increase social isolation [58], leading to individual mechanisms to cope with food insecurity such as a decrease in food intake instead of social support. A study on urban food insecure women in Toronto, Canada, found social isolation significantly associated with food insecurity and hunger [59]. Support systems may be stronger and tighter in rural areas than urban areas [60]; increasing the availability of food sharing and informal resources as a result.

Second, existing barriers, such as limited transportation options, may limit access to food resources among urban food insecure populations, consequently leading to the increased use of coping mechanisms such as skipping meals. Despite the perception that urban people have greater access to food resources than rural people, urban food insecure individuals may be hampered by other inequalities limiting food access, food availability, and food quality [39,61]. For example, food prices have been shown to be higher in some stores in low-income neighborhoods than higher income neighborhoods [62]. There may also be a greater number of food outlets and services and greater access to private transportation in wealthier neighborhoods than poorer neighborhoods [63]. Such barriers, including limited transportation and low-income, may increase the likelihood of reducing food intake as a coping mechanism.

\section{Discussion}

Using data from the ACS and the NLSCY, the prevalence of hunger was found to be higher among Aboriginal children than Canadian children in general. Coping strategies to hunger also differed. Urban and rural food insecure Inuit, Métis, and off-reserve First Nation children generally coped with 
hunger through an informal form of coping, i.e., social support. Similarly, rural food insecure Canadian children coped with hunger through social support. However, a majority of urban food insecure Canadian children coped with hunger through a different form of informal coping, that is, a reduction in food intake. Most parents of children did not report using a formal coping mechanism, such as institutional assistance, to cope with hunger, though significant urban-rural differences were found.

An increase in food resources through social support may increase food access, food availability, and food quality among both Aboriginal and rural Canadian children. Particularly for Aboriginal children, food sharing practices may increase the access and availability of traditional or other foods, as well as possibly increasing the quality of food intake. Food sharing practices represent community collectivity, respect, and cultural value among Aboriginal people [43] and a sense of community and collectiveness among rural individuals in general [51]. The social and cultural significance of food sharing practices have increased coping strategies for food insecurity and hunger among Aboriginal and rural Canadian groups; it would be of interest to further investigate food sharing practices and other cost-effective informal coping mechanism (e.g., community gardens) to food insecurity and hunger among urban Aboriginal and Canadian groups.

For urban Canadian children, a decrease in food intake to cope with hunger (e.g., skipping meals) may be influenced by barriers faced by urban food insecure people. Barriers to food access and availability include limited transportation to food outlets, higher prices in low-income neighborhoods, social stigma, and socio-economic disparities [39,61,63]. Despite the availability of institutional resources in some urban centers, such barriers may have increased inaccessibility for urban food-insecure individuals, similar to the inaccessibility faced in rural and remote locations. Thus, a decrease in food access, food availability, and food quality coupled with a reduction in food consumption, limited informal support, and changes in dietary habits may further exacerbate food insecurity among urban food insecure groups.

Food access, food availability, and food quality are driven by underlying factors related to socio-economic status and cultural and social networks. The geographical differences found in the present study are not solely due to urban-rural differences but rather the contextual factors of communities. Contextual factors such as social support may influence coping mechanisms, which in turn influence the level of food insecurity and hunger.

While social support, institutional assistance, and reduced food intake were the coping strategies examined in the present report, they are not the only coping strategies available to deal with food insecurity. Other coping mechanisms include increasing financial resources, shopping strategies, and managing food supply [64]. These coping strategies may increase food options for food insecure individuals, though such mechanisms may not necessarily eliminate the issue of hunger [65]. Certain coping mechanisms may temporarily increase access to food resources, but when such resources are depleted, individuals may resort (back) to reducing food intake to deal with food insecurity, further exacerbating the issue itself.

A limitation of the present review is the use of self/parent-reported data from the ACS and NLSCY. It is possible that due to social perceptions (with using institutional food banks, for example), respondents may refrain from reporting on the use of such coping mechanisms for food insecurity and hunger. Thus, results may not fully represent the prevalence of hunger and the use of coping strategies 
among food insecure groups. There is a need to gather other forms of data on coping mechanisms that is not self/parent-reported, such as administrative data on the locations, availability, and use of institutional programs. Nonetheless, this review provides insight on the reported use of various formal and informal coping mechanisms to deal with hunger in Canada by Aboriginal, Canadian, urban, and rural children.

\section{Conclusions}

Food security and hunger are important issues among Aboriginal children in particular, with known associations between food security and child health. The current report suggests differences in three types of coping strategies, i.e., seeking help from institutions, seeking assistance from relatives and/or friends, and skipping meals and/or cutting back on food consumption, among Inuit, Métis, and off-reserve First Nation children compared with Canadian children. Furthermore, differences were found between those living in urban versus rural areas, suggesting that coping with hunger may differ based on urban or rural contexts. However, differences in the use of coping mechanisms may not necessarily be a result of food insecurity by geographical location but rather a reflection of cultural and social customs; this theory needs further exploration in future studies. Recommendations for future studies include a more in-depth investigation of formal and informal mechanisms, including specific food sharing strategies (e.g., community gardens), cultural activities, and the use of food trading as a means to satisfy nutritional needs. It would also be of interest to examine these differences with a geographical lens, particularly as they relate to access, availability, and quality of food resources among food insecure groups and to take into consideration the influences of socioeconomic status.

\section{Acknowledgements}

We would like thank Evelyne Bougie from the Health Analysis Division, Statistics Canada, for her assistance in gathering relevant literature for the study.

\section{Author Contributions}

All authors have contributed to the conception and design of the study. Leanne Findlay performed the statistical analyses of the study. Benita Tam drafted the manuscript, with the assistance of Leanne Findlay and Dafna Kohen. All authors read and approved the final manuscript.

\section{Conflicts of Interest}

The authors declare no conflict of interest.

\section{References}

1. FAO, World Food Summit. Panel of eminent experts on ethics in food and agriculture. Available online: http://www.Fao.Org/docrep/014/i2043e/i2043e02e.Pdf. (accessed on 1 February 2014).

2. Frongillo, E.A. Validation of measures of food insecurity and hunger. J. Nutr. 1999, 129, 506S-509S. 
3. Willows, N.D.; Veugelers, P.; Raine, K.; Kuhle, S. Prevalence and sociodemographic risk factors related to household food security in Aboriginal peoples in Canada. Public Health Nutr. 2009, 12, 1150-1156.

4. McIntyre, L.; Glanville, N.T.; Officer, S.; Anderson, B.; Raine, K.D.; Dayle, J.B. Food insecurity of low-income lone mothers and their children in Atlantic Canada. Can. J. Public Health 2002, 93, 411-414.

5. Cafiero, C. Advances in Hunger Measurement. In Proceedings of the International Scientific Symposium on Measurement and Assessment of Food Deprivation and Undernutrition, Rome, Italy, 17-19 January 2012. Available online: http://www.foodsec.org/fileadmin/user_upload/eufao -fsi4dm/docs/Green_Room_Jan_17_panel_1_Cafiero. pdf (accessed on 1 February 2014).

6. Nord, M.; Hopwood, H. Recent advances provide improved tools for measuring children's food security. J. Nutr. 2007, 137, 533-536.

7. Maxwell, D.; Caldwell, R.; Langworthy, M. Measuring food insecurity: Can an indicator based on localized coping behaviors be used to compare across contexts? Food Policy 2008, 33, 533-540.

8. Corbett, J. Famine and household coping strategies. World Dev. 1988, 16, 1099-1112.

9. Hamelin, A.-M.; Habicht, J.-P.; Beaudry, M. Food insecurity: Consequences for the household and broader social implications. J. Nutr. 1999, 129, 525S-528S.

10. Cook, J.T.; Frank, D.A.; Berkowitz, C.; Black, M.M.; Casey, P.H.; Cutts, D.B.; Meyers, A.F.; Zaldivar, N.; Skalicky, A.; Levenson, S. Food insecurity is associated with adverse health outcomes among human infants and toddlers. J. Nutr. 2004, 134, 1432-1438.

11. Casey, P.H.; Szeto, K.L.; Robbins, J.M.; Stuff, J.E.; Connell, C.; Gossett, J.M.; Simpson, P.M. Child health-related quality of life and household food security. Arch. Pediatrics Adolesc. Med. 2005, 159, 51-56.

12. Jyoti, D.F.; Frongillo, E.A.; Jones, S.J., Food insecurity affects school children's academic performance, weight gain, and social skills. J. Nutr. 2005, 135, 2831-2839.

13. Olson, C.M. Nutrition and health outcomes associated with food insecurity and hunger. J. Nutr. 1999, 129, 521S-524S.

14. Ford, J.D. Vulnerability of Inuit food systems to food insecurity as a consequence of climate change: A case study from Igloolik, Nunavut. Reg. Environ. Chang. 2009, 9, 83-100.

15. Power, E.M. Conceptualizing food security for Aboriginal people in Canada. Can. J. Public Health 2008, 99, 95-97.

16. Lambden, J.; Receveur, O.; Marshall, J.; Kuhnlein, H.V., Traditional and market food access in Arctic Canada is affected by economic factors. Int. J. Circumpolar Health 2006, 65, 307-319.

17. Pinstrup-Andersen, P. Food security: Definition and measurement. Food Secur. 2009, 1, 5-7.

18. Garasky, S.; Morton, L.W.; Greder, K.A. The food environment and food insecurity: Perceptions of rural, suburban, and urban food pantry clients in Iowa. Fam. Econ. Nutr. Rev. 2004, 16, 41-48.

19. Nord, M.; Andrews, M.S.; Carlson, S.; Assistance, F. Household Food Security in The United States, 2004; US Department of Agriculture, Economic Research Service: Washington, DC, USA, 2002.

20. Morton, L.W.; Bitto, E.A.; Oakland, M.J.; Sand, M. Accessing food resources: Rural and urban patterns of giving and getting food. Agric. Hum. Values 2008, 25, 107-119. 
21. Garrett, J.L.; Ruel, M.T. Are determinants of rural and urban food security and nutritional status different? Some insights from Mozambique. World Dev. 1999, 27, 1955-1975.

22. Coveney, J.; O’Dwyer, L.A. Effects of mobility and location on food access. Health Place 2009, 15, 45-55.

23. Rose, D., Economic determinants and dietary consequences of food insecurity in the United States. J. Nutr. 1999, 129, 517S-520S.

24. Beaumier, M.C.; Ford, J.D. Food insecurity among Inuit women exacerbated by socioeconomic stresses and climate change. Can. J. Public Health 2010, 101, 196-201.

25. Dast Giri, S.; Mahboub, S.; Toutounchi, H.; Ostad Rahimi, A. Determinants of food insecurity: A cross-sectional study in Tabriz. J. Ardabil Univ. Med. Sci. (JAUMS) 2006, 6, 233-239.

26. Slack, T.; Myers, C.A. Understanding the geography of food stamp program participation: Do space and place matter? Soc. Sci. Res. 2012, 41, 263-275.

27. Statistics Canada. Census metropolitan influenced zone (MIZ). Available online: http://www12.Statcan.Gc.Ca/census-recensement/2011/ref/dict/geo010-eng.Cfm (accessed on 1 May 2014).

28. Findlay, L.C.; Janz, T.A. The health of Inuit children under age 6 in Canada. Int. J. Circumpolar Health 2012, 71, 1-9.

29. Findlay, L.C.; Janz, T. Health of First Nations children living off reserve and Métis children younger than age 6. Health Rep. 2012, 23, 1-10.

30. Loopstra, R.; Tarasuk, V. The relationship between food banks and household food insecurity among low-income Toronto families. Can. Public Policy 2012, 38, 497-514.

31. Vozoris, N.T.; Tarasuk, V.S. Household food insufficiency is associated with poorer health. J. Nutr. 2003, 133, 120-126.

32. Kirkpatrick, S.I.; Tarasuk, V. Assessing the relevance of neighbourhood characteristics to the household food security of low-income Toronto families. Public Health Nutr. 2010, 13, 1139-1148.

33. Goetz, S.J.; Rupasingha, A.; Zimmerman, J.N. Spatial food stamp program participation dynamics in US counties. Rev. Reg. Stud. 2004, 34, 172-190.

34. Ford, J.D.; Bolton, K.; Shirley, J.; Pearce, T.; Tremblay, M.; Westlake, M. Mapping human dimensions of climate change research in the Canadian Arctic. Ambio 2012, 41, 808-822.

35. Ford, J.D.; Lardeau, M.-P.; Blackett, H.; Chatwood, S.; Kurszewski, D. Community food program use in Inuvik, Northwest Territories. BMC Public Health 2013, 13, 1-15.

36. Skinner, K.; Hanning, R.M.; Desjardins, E.; Tsuji, L.J. Giving voice to food insecurity in a remote indigenous community in Subarctic Ontario, Canada: Traditional ways, ways to cope, ways forward. BMC Public Health 2013, 13, 1-13.

37. Quandt, S.A.; Arcury, T.A.; Bell, R.A.; McDonald, J.; Vitolins, M.Z. The social and nutritional meaning of food sharing among older rural adults. J. Aging Stud. 2001, 15, 145-162.

38. Theophano, J.; Curtis, K. Sisters, mothers and daughters: Food exchange and reciprocity in an Italian-American community. Diet. Domest. Life Soc. 1991, 147-171.

39. Ruel, M.T.; Garrett, J.L.; Hawkes, C.; Cohen, M.J. The food, fuel, and financial crises affect the urban and rural poor disproportionately: A review of the evidence. J. Nutr. 2010, 140, 170S-176S. 
40. Egeland, G.; Faraj, N.; Osborne, G. Cultural, socioeconomic, and health indicators among Inuit preschoolers: Nunavut inuit child health survey, 2007-2008. Rural Remote Health 2010, 10, 1-13.

41. Collings, P.; Wenzel, G.; Condon, R.G. Modern food sharing networks and community integration in the central Canadian Arctic. Arctic 1998, 51, 301-314.

42. Colby, S.E.; McDonald, L.R.; Adkison, G. Traditional native american foods: Stories from northern plains elders. J. Ecol. Anthropol. 2012, 15, 65-73.

43. Chakraborty, R.N. Sharing culture and resource conservation in hunter-gatherer societies. Oxford Econ. Papers 2007, 59, 63-88.

44. Wenzel, G.W. Canadian inuit subsistence and ecological instability-If the climate changes, must the Inuit? Polar Res. 2009, 28, 89-99.

45. Epple, C.; Wright, A.L.; Joish, V.N.; Bauer, M. The role of active family nutritional support in Navajos’ type 2 diabetes metabolic control. Diabetes Care 2003, 26, 2829-2834.

46. CMHC (Canada Mortgage and Housing Corporation). An Examination of the Use of Domestic Space by Inuit Families Living in Arviat, Nunavut; Research Highlights; Socio-economic Series 04-031; Canada Mortgage and Housing Corporation: Ottawa, ON, Canada, 2004.

47. Eriksson, B.S.; Rosenqvist, U. Social support and glycemic control in non-insulin dependent diabetes mellitus patients: Gender differences. Women Health 2003, 20, 59-70.

48. Garasky, S.; Morton, L.W.; Greder, K.A. The effects of the local food environment and social support on rural food insecurity. J. Hunger Environ. Nutr. 2006, 1, 83-103.

49. Meert, H. Rural community life and the importance of reciprocal survival strategies. Sociol. Rural. 2000, 40, 319-338.

50. Hofferth, S.L.; Iceland, J. Social capital in rural and urban communities. Rural Sociol. 1998, 63, 574-598.

51. Lee, G.R.; Coward, R.T.; Netzer, J.K. Residential differences in filial responsibility expectations among older persons. Rural Sociol. 1994, 59, 100-109.

52. McIntyre, L.; Connor, S.K.; Warren, J. Child hunger in canada: Results of the 1994 national longitudinal survey of children and youth. Can. Med. Assoc. J. 2000, 163, 961-965.

53. Findlay, L.C.; Langlois, K.A.; Kohen, D.E. Hunger among Inuit children in Canada. Int. J. Circumpolar Health 2013, 72, 1-9.

54. Bauer, K.W.; Widome, R.; Himes, J.H.; Smyth, M.; Rock, B.H.; Hannan, P.J.; Story, M. High food insecurity and its correlates among families living on a rural American Indian reservation. Am. J. Public Health 2012, 102, 1346-1352.

55. Mammen, S.; Bauer, J.W.; Richards, L. Understanding persistent food insecurity: A paradox of place and circumstance. Soc. Ind. Res. 2009, 151-168.

56. Sinha, D.; Tripathi, R.C. Individualism in a Collectivist Culture: A Case of Coexistence of Opposites Individualism and Collectivism: Theory, Method, and Applications; Sage Publications: Thousand Oaks, USA, 1994; pp. 123-136.

57. Triandis, H.C.; McCusker, C.; Hui, C.H., Multimethod probes of individualism and collectivism. J. Personal. Soc. Psychol. 1990, 59, 1006-1020.

58. Galtung, J. On the social costs of modernization: Social disintegration, atomie/anomie and social development. Dev. Chang. 1996, 27, 379-413. 
59. Tarasuk, V.S. Household food insecurity with hunger is associated with women's food intakes, health and household circumstances. J. Nutr. 2001, 131, 2670-2676.

60. Gore, S. The effect of social support in moderating the health consequences of unemployment. J. Health Soc. Behav. 1978, 19, 157-165.

61. Koc, M.; Macrae, R.; Mougeot, L.J.A.; Welsh, J. For Hunger-Proof Cities: Sustainable Urban Food Systems; International Development Research Centre: Ottawa, ON, Canada, 1999.

62. Latham, J.; Moffat, T. Determinants of variation in food cost and availability in two socioeconomically contrasting neighbourhoods of Hamilton, Ontario, ON, Canada. Health Place 2007, 13, 273-287.

63. Morland, K.; Wing, S.; Diez Roux, A.; Poole, C. Neighborhood characteristics associated with the location of food stores and food service places. Am. J. Prev. Med. 2002, 22, 23-29.

64. Kempson, K.; Keenan, D.P.; Sadani, P.S.; Adler, A. Maintaining food sufficiency: Coping strategies identified by limited-resource individuals versus nutrition educators. J. Nutr. Educ. Behav. 2003, 35, 179-188.

65. Hoisington, A.; Shultz, J.A.; Butkus, S. Coping strategies and nutrition education needs among food pantry users. J. Nutr. Educ. Behav. 2002, 34, 326-333.

(C) 2014 by the authors; licensee MDPI, Basel, Switzerland. This article is an open access article distributed under the terms and conditions of the Creative Commons Attribution license (http://creativecommons.org/licenses/by/3.0/). 